УДК 338.1

DOI: $10.14451 / 1.193 .114$

\title{
АНАЛИЗ ОТКЛОНЕНИЙ ЭКОНОМИЧЕСКОГО РОСТА
}

\author{
(c) 2020 Парушев Александр Валерьевич \\ доктор философии \\ Высшая школа предпринимательства, Россия, Тверь \\ E-mail: paruchev@mail.ru
}

Данная статья описывает отклонения национальных траекторий от мировой траектории развития. И это является предметом анализа. Гипотеза, которую выдвигает автор и последовательно доказывает автор, состоит в том, что социалистическая экономика конечна. Предметом рассмотрения статьи являются отклонения экономического роста от стандартных норм в странах импортозамещения. Такие страны как Северная Корея, Куба и Лаос используют данную модель и в этом заключается актуальность данной статьи.

Ключевые слова: экономический рост, темп роста, ВВП, доходность на душу населения, государственные доходы и расходы, экспорт, импорт, урбанизация, конвертируемость валюты, импортозамещение, протекционизм, бюджет.

Великий известный экономист С.Кузнец определил понятие экономического роста как экономическое развитие, при котором темпы роста производства в долгосрочном периоде постоянно превышают темпы роста населения $[1,8]$. Это явилось большой новостью для мировой экономической теории. В большинстве стран рост производства осуществлялся приблизительно одинаковыми темпами с ростом населения, причем при относительно низких доходах Можно предположить, что утверждение С.Кузнеца имеет конкретные временные границы: ВВП на душу населения не может по длительности бесконечно превышать темпы роста населения в силу ограниченности ресурсов [2,9]. Отсюда следует, что существуют переходный период, когда экономический рост является переходом из одного состояния (аграрное общество) в другое (постиндустриальное общество с достаточно высоким уровнем доходности на душу населения). Экономическая теория указывает на существование неевропейских очагов современного роста. Только экономический подъем, а также появление и распространения институциональных инноваций, считалось, проявляют уверенный рост. Зависимость результатов экономического роста от формирования капиталистических отношений, развития рынка, появление гарантий частной собственности не вызывает сомнений [3]. Характерными чертами такого роста являются снижение доли сельского хозяйства в объеме производства; стремительный рост городов; увеличение грамотного на- селения, и, как следствие, повышение уровня образования; снижение рождаемости, которое вызывает снижение темпов роста населения; увеличение и рост продолжительности жизни; рост сбережений; уменьшение доли продовольственных товаров в совокупном потреблении; рост государственных расходов в ВВП [4]. Данные процессы имели место на фоне преобладания экспорта над импортом.

В наши дни экономический рост, который обеспечивает повышение ВВП на душу населения с 300 долларов в доиндустриальных странах (уровень Перу) до 4-4,5тыс. долларов в высокоразвитых странах (Великобритания, Швейцария) сопровождается огромной нагрузкой на экономику, доля государственных расходов с 7-9\% возрастает до 40\%, повышается уровень образования (количество образованных людей от 35\% возрастает до 90-92\%). Одновременно происходит снижение доли сельского хозяйства в структуре производства с $47 \%$ до 7-8\% и занятости (с 60-65\% до 18-20\%), растет уровень открытости экономики - растет доля экспорта в ВВП с 10-12\% до 35-40\%, наблюдается рост сбережений с $10-12 \%$ до $30-35 \%$, снижение рождаемости с $28-30 \%$ до $7-9 \%$ и смертности с $28-30 \%$ до 7-9\%, темпы прироста населения снижаются. [10] Анализ ранних стадий индустриализации показывает высокую степень неравенства, особенно в странах выше 1000 долларов/чел., затем наблюдается его снижение. Также хорошо проявляется зависимость экономического развития и политического развития. Страны с более 
высоким экономическим развитием проявляют большую склонность к демократическим принципам, проявляющиеся в более высоком уровне образования, доминирования среднего класса уровня жизни, урбанизацией.

Таким образом, можно говорить о некоторых оценках по критериям, с помощью которых можно получить некоторое представление о данной стране, задав эти критерии. К примеру, если страна с высоким уровнем экспорта (больше 20\%), с низким уровнем занятых в сельском хозяйстве людей (меньше 20\%), то можно с высокой долей вероятности утверждать, что данная страна с высоким среднедушевым ВВП, с высоким уровнем урбанизации, достаточно высоким уровнем грамотности и здорового населения, достаточно с медленным приростом населения и низкой рождаемостью и смертностью, а также страна, которая, скорее всего, перераспределяет через свой бюджет не менее четверти ВВП (в т.ч. внебюджетные фонды). В плане политического развития данная страна, скорее всего, является страной с устойчивой демократией.

И, наоборот, если в стране доминирует доля населения, занятого в сельском хозяйстве, доля экспорта мала (меньше 1\%), то данную страну можно считать слаборазвитой страной со среднедушевым ВВП менее 500 долларов, малограмотным населением с высокой смертностью, низкими продолжительностью жизни, рождаемостью, и достаточно ограниченными сбережениями у населения. В политическом плане эта страна с ярко выраженной монархией или авторитарным режимом нестабильного характера.

Исследуя экономический рост, можно сказать, что он имеет непосредственную связь с национальной нормой сбережений и накоплений [11]. Увеличение государственных расходов в ВВП оказывает разное воздействие на экономику в целом, если оно происходит в пределах допустимых размеров. Однако выход за рамки допустимых размеров оказывает отрицательное воздействие на экономический рост.

Чтобы получить полную картину оценки экономического роста, необходимо учитывать культурные традиции общества, его особенности. Если выбирать жесткую траекторию развития, то можно упустить суть и последствия устойчивых отклонений национального развития от общемировых тенденций.

Экономический рост каждой страны уникален. Однако известно небольшое количество случаев, когда отклонения от общемировых тенденций развития экономического роста носили радикальный, устойчивый характер и определялись нехарактерными для большинства рыночных экономик конгломератом взаимосвязанных институциональных инноваций. В данной статье предметом анализа будут служить такие отклонения.

Сопоставляя фактические национальные траектории развития экономического роста стран с нормативными, можно выделить несколько групп стран с устойчивыми или отклоняющимися параметрами развития:

1. Страны с так называемой «шведской моделью». Это страны с развитой рыночной экономикой, но имеющие высокую долю государственных доходов и расходов в ВВП, очень дорогостоящие социальные программы и достаточно низкую дифференциацию доходов населения.

2. Страны, в которых государственная нагрузка на экономику достаточно низка, с высокими показателями долей частных сбережений и инвестиций в ВВП (в основном, это страны Юго-Восточной Азии)

3. Страны с закрытой экономикой, с весьма аномально низкими ресурсными показателями импорта в ВВП и экспорта продукции обрабатывающих отраслей (страны импортозамещения)

4. Страны с закрытой экономикой, характеризующиеся высокой долей государственных доходов и расходов в ВВП, высоких долей государственных сбережений и инвестиций в ВВП, достаточно высокие показатели ресурсоемкости в ВВП (КНР, Вьетнам, Куба, Северная Корея, Лаос)

Предметом рассмотрения в данной статье будут являться отклонения экономического роста от стандартных норм в странах с закрытой экономикой.

Исторически сложилось, что данная модель предшествовала формированию социалистической системы хозяйствования. Впервые она сложилась в России, затем в Бразилии, Аргентине, Индии, Мексике. Это большие, в основном, аграрные страны, имеющие внушительный внутренний рынок, имеющие характер догоняющего развития. В основном, это страны-экспортеры сельскохозяйственной продукции и сырья, со слабой обрабатывающей промышленностью, спрос на товары промышленного характера, в основном, удовлетворяется за счет импорта из индустриальных стран 
В такой ситуации кажется нормальной идея, которая ранее, еще в XIX в., обсуждалась в развивающихся странах - отменить внешнеэкономические рыночные механизмы, отказаться от конвертируемости валюты, ввести монополию на внешнюю торговлю, тем самым, сконцентрировав валютные ресурсы на приоритетных направлениях экономики. Таким образом, устраняется конкуренция импорта, внутренний рынок расширяется, что становится мощной мотивацией к формированию национальной обрабатывающей промышленности.

Выводу национального капитала препятствуют жесткий контроль за внешнеэкономической сферой, неконвертируемость валюты. Это позволяет использовать ресурсы национального капитала для финансирования международной промышленности. Сам внутренний рынок сохраняется (как механизм текущего микрорегулирования), но его значимость в формировании стратегии отраслевой экономической структуры серьезно ограничивается.

Сама стратегия импортозамещения и протекционизма достаточно привлекательна и проста. Таможенные пошлины - это достаточно крупные поступления в бюджет и характеризуются достаточной простотой сбора. Отсюда вытекает желание постоянно их увеличивать для решения бюджетных проблем. Постоянные проблемы с платежным балансом вынуждает ограничивать импорт. Модель стран импортозамещения ассоциируется с традициями аграрного государства. Данная модель не предполагает ликвидации частной собственности, а также четкого разграничения собственности и власти.

Модель стран импортозамещения можно обозначить как естественную реакцию национальных властных элит. Для того, чтобы она была реализована, не нужны радикальные изменения в распределении власти и собственности.

Хочется отметить главное отличие данной модели: переход от простой тарифной защиты внутреннего производителя к фактическому отделению внутреннего рынка от внешнего. С этой целью вводятся экстремально высокие тарифы, которые не позволяют реализовать рыночную интеграцию национального частного сектора в общую структуру мировой торговли, а также различные формы прямого рационирования конвертируемой валюты и сама монополия внешней торговли.

С целью выявить характерные траектории стран импортозамещения выделим те страны, которые:

1. По Дж.Саксу и Э.Урнеру [5] были с закрытыми экономиками.

2. На протяжении длительного периода (1960-2018) доля экспорта ВВП составляла менее или около $10 \%$.

Такими примерами являются Бангладеш, Аргентина, Мексика, Мьянма, Пакистан, Бразилия, Индия.

Когда страна придерживается стратегии импортозамещения, темпы роста экспорта отстают от темпов роста промышленного производства и ВВП. Отсюда отношение экспорта к ВВП с ростом экономики снижается. В процентном соотношении эта доля варьируется в диапазоне 5-10\%. [11]

Существует также корреляционная связь между темпами экономического роста и темпами роста экспорта. Дополнительную мотивацию к экономическому росту создаст выход на мировой рынок. Не существует стран, идущих по пути экономического роста и не участвующих в мировом разделении труда. Существует предельный уровень изоляции (порядка 4\%) экспорта, выходя за пределы которого становится невозможным устойчивое развитие, а показатели приростной капиталоемкости ВВП стремятся к бесконечности.

Мнение о том, что импортозамещение может дать возможность снять ограничение экономического роста, которые связаны с импортом, дефицитностью платежного баланса, валютных резервов, ошибочно. Импорт промышленных товаров действительно сокращается, но зато появляется необходимость в импорте сырья и полуфабрикатов.

Существуют границы закрытости экономики, что доказывает опыт стран импортозамещения. Достигнув максимума, доля экспорта в ВВП стабилизируется, но появляются такие проблемы как дефицит конвертируемости валюты, борьба вокруг ее распределения. В данных условиях экономический рост возможен только за счет экспортных поступлений. Резервы снижения доли экспорта в ВВП исчерпаны.

Таким образом, стратегия импортозамещения обладает некоторыми верхним и нижним пределами. Она позволяет обеспечить промышленный рост по причине ограничения конкуренции импортных товаров. Но в то же время существуют заданные ей самой пределы, за вы- 
ходы которых экономическое развитие становится невозможным.

Когда страна ориентируется на импортозамещение, это дает ей «тепличные» условия. Эти условия сильно отличаются от тех жестких реалий, которые существуют на мировых рынках. Мягкость экономической среды, в которых производится продукция, дает предприятиям возможность существовать при хронически низком качестве продукции, неэффективно использовать ресурсы. Все это создает новые управленческие стереотипы, которые не входят ни в какое сравнение со стереотипами на международных рынках. Отсутствие конкуренции влечет за собой низкую конкурентоспособность отечественной обрабатывающей промышленности [6].

В экспорте существуют 2 разных блока: экспорт сырья и экспорт продукции обрабатывающих отраслей. Экспорт сырья зависит от наличия ресурсов в этой стране, экспорт продукции определяется конкурентоспособностью [7] ее на мировом рынке, институциональных инноваций, которые связаны с выбранной моделью роста.

Для стран с избранной стратегией импортозамещения характерны очень низкие показатели экспорта продукции на душу населения по сравнению с государствами соответствующего уровня. При этом следует особенно отметить, что отличие от параметров, которые присущи высокоразвитым странам, с ростом ВВП на душу населения не только не уменьшается, а даже увеличивается.

Возможности наращивания экспорта сырья в стране, богатой природными ресурсами имеет пределы для стран, выбравших стратегию импортозамещения, пределы увеличения ВВП ограничены, с одной стороны, отношением ВВП к сырьевому экспорту, с другой- максимальным объемом экспорта сырья на душу населения.

Пределы роста для стран, очень богатых природными ресурсами, по истине могут быть очень высокими, но, в любом случае, они ограничены обозначенными выше наборами факторов.

Выход на экономический рост в этой ситуации возможен, если страна выйдет на международное разделение труда на уровне обрабатывающих отраслей. Но как раз это сделать и не удается. Достигая верхнего предела значений отношения ВВП к экспорту на душу населения и экспорта сырья на душу населения отмечается замедление экономического роста и его неу- стойчивость.

На практике попытки вывести объемы производства, совместимые с ее устойчивым функционированием, не меняя модели, обычно приводили к еще худшему положению. Оно заключалось в масштабном заимствовании, которое на короткий срок позволяло снять валютные ограничения и приподнять экономику. Но в силу неустойчивости источников финансирования, невозможности быстро погасить задолженность за счет быстрорастущей конкурентоспособности экспорта продукции приводили к тупиковым ситуациям и вгоняли экономику в еще большую стагнацию.

Сигналом о кризисе стратегии импортозамещения служит тяжелый валютный кризис, дефицит конвертируемой валюты для поддержания национальной промышленности.

Единственным выходом из сложившейся ситуации заключается в выходе на международный рынок, открытия экономики, конвертируемости валюты, отсутствии протекционистской политики в отношении внутреннего рынка. Но неизбежно промежуточным результатом будет структурный кризис, спад производства, который невозможно моментально устранить и поднять до уровня конкурентоспособности продукции на мировом рынке.

Выбрать и войти в режим импортозамещения стране легко, выйти - задача куда сложнее.

Стагнация, описанная выше, неизбежна. Период стагнации может занимать десятки лет (так называемые переходный период).

Из истории развития многих стран преимущества стратегии импортозамещения объяснялись защитой экономики от колебаний на внешнем рынке, желанием быть более независимой страной. И везде необходимость выхода из этой модели сопровождался острым кризисом платежного и торгового балансов, а также недостатком валюты для обеспечения минимального импорта.

Следует отметить, что выход из импортозамещающей модели у бедных ресурсами стран происходит гораздо проще по причине выхода на более ранних этапах. На ранних этапах при низком уровне ВВП демонтаж механизмов импортозамещения и запуск рыночных регуляторов происходит гораздо легче, чем у развитых стран и могут с легкостью сочетаться с экономическим ростом. Для богатых ресурсами стран относительно высокого уровня доходов на душу 
населения динамика механизмов импортозамещения неизбежно сопровождается серьезными экономическими кризисами, которые могут занимать десятилетия.

\section{Выводы:}

1. Иерархичность системы в стране вместо рыночных механизмов позволяет сильно расширить возможности перераспределения ресурсов. Что влечет за собой стремительный темп роста занятости и объема производства

2. Как только социалистическая модель исчерпает резервы из традиционного сектора, она начинает давать сбои. И проявляется это в первых признаках появления внутренних ограничений: повышении энергоемкости, низкой конкурентоспособности, вызванной закрытостью экономики; отсутствием динамики в экономике, которые в совокупности ведут к снижению экономического роста и понижению капиталоотдачи.

3. Появляющиеся внутренние ресурсные ограничения богатые ресурсами страны получают возможность более безболезненно пройти путь выхода их из социалистической модели к рыночным отношениям, чем богатые ресурсами страны

4. Выйти из социалистической модели можно лишь на ранней стадии, пока еще существует потенциал в традиционном секторе. Как только этот резерв будет исчерпан, экономический рост будет возможен при серьезной перестройке структуры индустрии, которая неизбежно будет сопровождаться падением объема производства.

\section{Библиографический список}

1. Kuznets, $S$. Total Output and Production Structere. Cambrige, 1971

2. Meadows S.D., Meadows D. L., Randers, J, Behrens W.H. Beyond the limits.Postmills, 1992

3. Jones E. The European Miracle: Environments Economies and Geopolitics in the History of Europe and Asia. Cambridge, 1987

4. Parushev A. V. Impact of Macroeconomic Factors on Strategic Choice of Companies Health and Beauty industry// Today and tomorrow of the Russian economy. 2019№ 93-94 P.41-51 DOI:10.26653/1993-4947-2019-93-94-04

5. Sash J., Warner A. Economic Reform and the Process of Global Integration. NBER Reprint, № 2002.1995, p.22

6. Parushev A. V. Excellence in production on the example of companies "Meteorite Group" and "Planet Fintess" // Journal of Economy and entrepreneurship, Vol.13, Nom.5 pp.1096-1102, 2019

7. Parushev A.V. Basic concepts of a company's market orientation in the fitness industry Vologda Regional Sector by the Example of 'Meteorite Group”// Science rewiew theory and practice, ISSN № 2226-0226 Vol.9, Issue 10,2019, pp $1568-1583$

8. Kuznets S. Modern Economic Growth: Rate, Structure and Spread. New Haven. London, 1966

9. Meadows S.D., Meadows D. L., Randers, J, Behrens W.H The Limits to Grouth. New York,1974

10. Е.А.Звонова, М.В.Ершов, М.В.Кузнецов, А. В.Навой, В.Я. Пищик «Реформирование мировой финансовой архитектуры и российский финансовый рынок» Изд.: М.: РУСАЙНС, 2016-430с.

11. Е.Гайдар. «Аномалии экономического роста» Журнал «Вопросы экономики» № 12, 1996 г. 